\title{
POPULAÇÃO E TERRITÓRIO: VARIÁVEIS DEMOGRÁFICAS E PROCESSOS SOCIOESPACIAS NO RIO GRANDE DO NORTE
}

\author{
Ione Rodrigues Diniz Morais ${ }^{1}$ \\ Eugênia Maria Dantas ${ }^{2}$
}

\section{Resumo}

Este estudo objetiva analisar as interrelações entre a dinâmica do crescimento e da distribuição da população e os processos socioespaciais que afetaram o território do Rio Grande do Norte entre 1872 a 2010, a partir de uma abordagem conceitual sobre população, território e reestruturação em uma perspectiva histórica, que envolveu pesquisa bibliográfica e documental. Até o Censo de 1900, o crescimento da população total do estado apresentava um padrão estável, assumindo uma escala ascendente a partir de 1920. Já os padrões de comportamento da população rural e urbana apresentaram tendências opostas. A população rural registrou crescimento até o Censo de 1970 e, a partir deste, apresentou tendência declinante. A população urbana manteve a propensão de aumento, passando a ser predominante no Censo de 1980. Foi no contexto da reestruturação produtiva, nos anos de 1980, que se consolidou a transição de um perfil demográfico e econômico marcadamente rural/agrário para urbano/terciário.

Palavras-chave: População, território, processos socioespaciais.

\section{POPULATION AND TERRITORY: DEMOGRAPHIC VARIABLES AND SOCIOESPACIAS PROCESSES IN RIO GRANDE DO NORTE}

\begin{abstract}
This study aims to analyze the relationships between the dynamics of population growth and distribution and the socio-spatial processes that affect Rio Grande do Norte territory from 1872 to 2010, from a conceptual approach on population, territory and restructuring in a historical perspective, which involved bibliographical and documentary research. Based on the Censo 1900, a stable growing of the population in the State, with an ascendant scale since in 1920. Related to the behavior pattern of the rural and urban population, they present opposite tendencies. The rural population presented a growth until Censo 1970 and, after that, it had a tendency to decrease. The urban population kept growing, until be predominant in the Censo 1980. It was in the context of the productive restructure, in the 80s, that had a transition from an economic and demographic profile basically rural/agrarian to the urban/tertian.
\end{abstract}

Keywords: Population, territory, socio-spatial processes.

\footnotetext{
${ }^{1}$ Professora do Departamento de Geografía-CCHLA/UFRN e docente permanente do Programa de Pósgraduação e Pesquisa em Geografia (PPGe) e de Pós-Graduação em Geografia (GEOPROF). E-mail: ionerdm@yahoo.com.br.

${ }^{2}$ Professora do Departamento de Geografía-CCHLA/UFRN e docente permanente do Programa de Pósgraduação e Pesquisa em Geografia (PPGe) e de Pós-Graduação em Geografia (GEOPROF). E-mail: eugeniadantas@yahoo.com.br.
}

Sociedade e Território - Natal. Vol. 29, N. 2, p. 84-100, Jul./Dez. de 2017. 


\section{POBLACIÓN Y TERRITORIO: VARIABLES DEMOGRÁFICAS Y PROCEDIMIENTOS SOCIALESPACIAS EN EL RÍO GRANDE DEL NORTE}

\section{Resumen}

Este estudio objetiva analisar las interrelaciones entre la dinámica del crecimiento y la distribución de la población y los procesos socioespaciales que afectaran el territorio del Rio Grande do Norte entre 1872 a 2010, a partir de un enfoque conceptual sobre población, territorio y reestructuración desde una perspectiva histórica, que involucró investigación bibliográfica y documental. Hasta el Censo de 1900, el crescimiento de la población total del estado apresentaba un patrón estable, asumiendo una escala ascendiente a partir de 1920. Ya los patrones de comportamiento de la población rural y urbana presentaron tendencias opuestas. La población rural registró crecimiento hasta el Censo 1970 y, apartir de este, presentó tendencia declinante. La población urbana mantuvo la propensión de aumento, pasando a ser predominante en el Censo de 1980. Fue en el contexto de la reestructuración productiva, en los años de 1980, que se consolidó la transiión de un perfil demográfico y económico marcadamente rural/agrario para urbano/terciario.

Palabras clave: Población, território, procesos socioespaciales.

\section{INTRODUÇÃO}

A Ciência Geográfica tem nos estudos de população um importante campo de investigação, que pode ser desenvolvida a partir das variáveis crescimento, estrutura, distribuição espacial e as migrações.

O crescimento e a distribuição espacial da populacional, objeto desse estudo, são variáveis que devem ser consideradas para a análise do território. A variável crescimento populacional se define a partir dos componentes natalidade, mortalidade e migrações, os quais se constituem elementos que favorecem a problematização de processos socioespaciais de natureza e morfologia específicas. Esse conjunto de elementos produz implicações na distribuição da população pelo território, em termos de localização rural e urbana.

De acordo com Guertechin (1981, p. 63), “os estudos populacionais não se referem somente às variáveis demográficas, mas às relações entre a evolução da população e outras variáveis: econômicas, sociais, políticas, culturais". Nesse sentido, o território é a matriz que contem a dimensão física e material, sendo o território usado um conjunto de objetos e ações, “sinônimo de espaço humano, espaço habitado." (SANTOS, 1998, p. 16).

Com base nessa premissa, problematizou-se a relação entre população e território, elegendo o Rio Grande do Norte como referência de análise. Nessa investida, definiu-se Sociedade e Território - Natal. Vol. 29, N. 2, p. 84-100, Jul./Dez. de 2017. 
como objetivo analisar as interrelações existentes entre o crescimento e a distribuição da população e os principais processos históricos e socioeconômicos que afetaram o território do Rio Grande do Norte no período de 1872 a 2010.

Não obstante o reconhecimento de que o estado possui diferentes regionalizações, as quais são estabelecidas em função de interesses diversos, neste artigo, adotou-se a regionalização estabelecida para fins de planejamento, ou seja, aquela que serviu de base à elaboração dos Planos de Desenvolvimento Regional Sustentável. Exceção feita apenas à porção leste do território potiguar, visto que o plano elaborado contempla apenas a Região Metropolitana de Natal. Dessa forma, o recorte estabelecido para a Região Leste considerou os municípios que integram a Região Metropolitana e aqueles localizados em sua proximidade que não foram integrados em outros recortes regionais (Figura 1).

Figura 1: Divisão Regional do Rio Grande do Norte

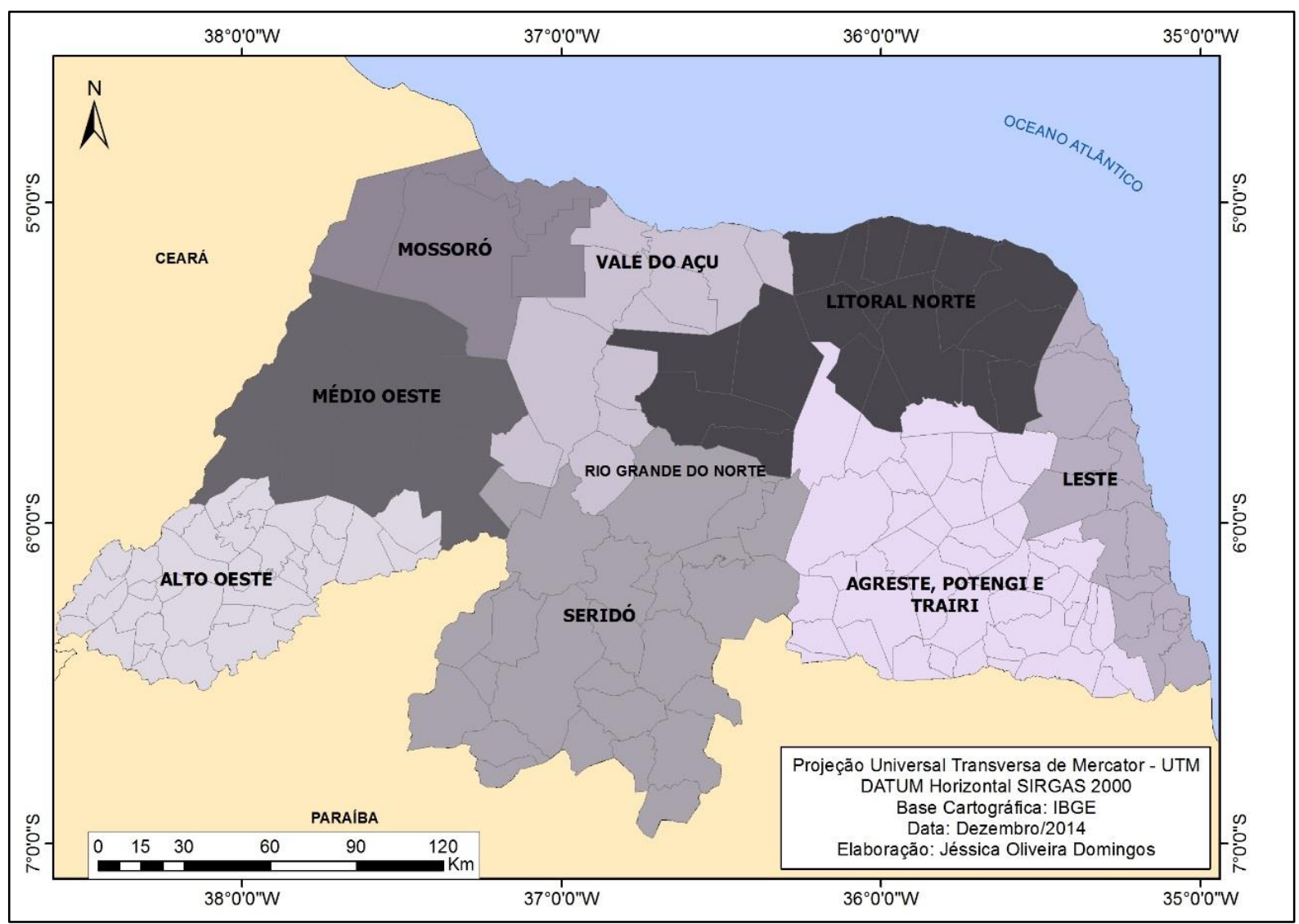

Fonte: Elaboração de Jéssica Oliveira Domingos (2014).

Os procedimentos metodológicos utilizados neste estudo corresponderam à pesquisa bibliográfica, sobretudo em livros e artigos que tratam da formação e estruturação territorial do Rio Grande do Norte, e à pesquisa documental com base nos planos de desenvolvimento 
sustentável para fins de definição da regionalização a ser $\operatorname{adotada}^{3}$ e em bancos de dados do Instituto Brasileiro de Geografia e Estatística (IBGE), que abrangem os censos populacionais realizados no país.

$\mathrm{O}$ artigo apresenta uma estrutura que compreende, inicialmente, uma breve sistematização sobre os aspectos históricos da organização territorial e dos recenseamentos populacionais do Brasil e suas repercussões no Rio Grande do Norte; em seguida, realiza-se a leitura da dinâmica populacional do Rio Grande do Norte, no período de 1872 a 2010, a partir de uma periodização estabelecida com base em processos históricos e sociais que repercutiram sobre o território potiguar e, por fim, apresenta-se um quadro geral da dinâmica populacional do estado em uma escala regional.

\section{NOTAS SOBRE A ORGANIZAÇÃO TERRITORIAL E OS CENSOS DEMOGRÁFICOS DO RIO GRANDE DO NORTE}

Considerando a importância da compreensão da dinâmica territorial para os estudos de população, foram sistematizadas breves notas sobre os aspectos históricos da organização

\footnotetext{
${ }^{3}$ Região Leste - 17 municípios: Arez, Baia Formosa, Canguaretama (Penha), Ceará-Mirim, Extremoz, Goianinha, Macaíba, Maxaranguape, Natal, Nísia Floresta, Parnamirim, Rio do Fogo, São Gonçalo do Amarante, São José de Mipibu, Senador Georgino Avelino, Tibau do Sul e Vila Flor; Região de Mossoró - 6 municípios: Areia Branca, Baraúna, Grossos, Mossoró, Serra do Mel e Tibau; Região do Vale do Açu - 10 municípios: Açu, Alto do Rodrigues, Carnaubais, Guamaré, Ipanguaçu, Itajá, Macau, Paraú, Pendências e São Rafael; Região do Litoral Norte - 18 municípios: Afonso Bezerra, Angicos, Caiçara do Norte, Fernando Pedroza, Galinhos, Jandaíra, Jardim de Angicos, João Câmara (Baixa Verde), Parazinho, Pedra Grande, Pedra Preta, Pedro Avelino, Poço Branco, Pureza, São Bento do Norte, São Miguel do Gostoso, Taipú e Touros; Região do Médio Oeste 10 municípios: Apodi, Campo Grande (Augusto Severo), Caraúbas, Felipe Guerra, Governador Dix-Sept Rosado, Itaú, Rodolfo Fernandes, Severiano Melo, Triunfo Potiguar e Upanema; Região do Alto Oeste - 36 municípios: Água Nova, Alexandria, Almino Afonso, Antônio Martins, Coronel João Pessoa, Doutor Severiano, Encanto, Francisco Dantas, Frutuoso Gomes, Janduís, João Dias, José da Penha, Lucrécia, Luís Gomes, Major Sales, Marcelino Vieira, Martins, Messias Targino, Olho D'água dos Borges, Paraná, Patu, Pau dos Ferros, Pilões, Portalegre, Rafael Fernandes, Rafael Godeiro, Riacho da Cruz, Riacho de Santana, São Francisco do Oeste, São Miguel, Serrinha dos Pintos, Taboleiro Grande, Tenente Ananias, Umarizal, Venha Ver e Viçosa; Região Agreste, Potengi e Trairi - 45 municípios: Barcelona, Bento Fernandes (Barreto), Bom Jesus, Brejinho, Caiçara do Rio do Vento, Campo Redondo, Coronel Ezequiel, Espírito Santo, Ielmo Marinho, Jaçanã, Boa Saúde (Januário Cicco), Japi, Jundiá, Lagoa Danta, Lagoa de Pedras, Lagoa de Velhos, Lagoa Salgada, Lajes (Itaretama), Lajes Pintadas, Montanhas, Monte Alegre, Monte das Gameleiras, Nova Cruz, Passa e Fica, Passagem, Pedro Velho, Porto do Mangue, Serra Caiada (Pres. Juscelino), Riachuelo, Rui Barbosa, Santa Cruz, Santa Maria, Santo Antônio; São Bento do Trairi, São José do Campestre, São Paulo do Potengi, São Pedro, São Tomé, Senador Elói de Souza (Caiada), Serra de São Bento, Serrinha, Sítio Novo, Tangará, Várzea e Vera Cruz; Região do Seridó - 25 municípios: Acari, Bodó, Caicó, Carnaúba dos Dantas, Cerro Corá, Cruzeta, Currais Novos, Equador, Florânia, Ipueira, Jardim de Piranhas, Jardim do Seridó, Jucurutu, Lagoa Nova, Ouro Branco, Parelhas, Santana do Matos, Santana do Seridó, São Fernando, São João do Sabugi, São José do Seridó, São Vicente, Serra Negra do Norte, Tenente Laurentino Cruz e Timbaúba dos Batistas.
}

Sociedade e Território - Natal. Vol. 29, N. 2, p. 84-100, Jul./Dez. de 2017. 
territorial e dos recenseamentos populacionais do Brasil e suas repercussões no Rio Grande do Norte.

O território brasileiro, ao longo de sua história, passou por reconfigurações, sendo um marco inicial a instituição das Capitanias Hereditárias, sistema de administração criado pelo Rei de Portugal, D. João III, em 1534. Com o objetivo de colonizar o Brasil, impedindo as invasões estrangeiras, esse sistema promoveu a divisão do território brasileiro em grandes faixas, que ficaram sob a administração de particulares, principalmente nobres que possuíam relações com a Coroa Portuguesa. Nesse contexto, o espaço que hoje corresponde ao estado potiguar integrava a Capitania do Rio Grande (esta era bem mais ampla que o atual território do estado). Em 1759, na administração do Marquês de Pombal (1750-1777), a organização espacial da Colônia foi modificada, sendo extinto o sistema de Capitanias Hereditárias (VIANNA, 1977).

Em 1799, quando teve início o governo do Príncipe Regente D. João, a divisão territorial correspondia a Capitanias Gerais e Capitanias Subalternas. Nesse cenário, a antiga Capitania Real do Rio Grande figurava como Capitania Subalterna sob o nome de Rio Grande do Norte. No entanto, a vinda da Família Real para o Brasil (1808) e sua consequente elevação à sede da monarquia suscitaram a necessidade de uma reorganização administrativa. No interior desse processo, o Rio Grande do Norte passou da condição de Capitania Subalterna para a categoria de Autônoma, situação mantida até o fim do sistema colonial.

No Brasil Império (1822-1889), o território foi reordenado mediante a instituição das províncias, as quais eram chefiadas por um presidente. Nesse ínterim, a capitania passou à condição de Província do Rio Grande do Norte.

Proclamada a República no Brasil, em 1889, novamente a divisão territorial e a estrutura administrativa foram redefinidas. A Constituição de 24 de fevereiro de 1891 (que vigorou até 1930) determinou que o país fosse constituído por uma federação de vinte estados, aos quais foram concedidas amplas autonomias - econômica e administrativa - e seria governado por um presidente eleito diretamente pelo povo, cumprindo mandato com duração de quatro anos (VIANNA, 1977). Nesse contexto, a província assumiu a condição de Estado do Rio Grande do Norte.

Os processos históricos que levaram o território do Brasil e, consequentemente, do Rio Grande do Norte a sucessivas reconfigurações evidenciaram a necessidade de se obter informações acerca da população, fazendo surgir iniciativas que levaram à realização de levantamentos demográficos.

Sociedade e Território - Natal. Vol. 29, N. 2, p. 84-100, Jul./Dez. de 2017. 
Conforme Oliveira e Simões (2005), o primeiro levantamento da população brasileira foi realizado em 1808, ano em que a Corte portuguesa chegou ao Brasil, e contabilizou um total de 4 milhões de habitantes. Todavia, foi a Lei n. 1829, sancionada em 1870, a primeira a determinar a realização de recenseamentos da população em escala nacional a cada dez anos. Tomando por base a referida lei, em 1872, foi realizado pela Diretoria Geral de Estatística do Ministério de Negócios do Império o primeiro Censo Nacional de População.

Em seguida, foram realizados os recenseamentos de 1890 e 1900, que se apresentaram problemáticos quanto à sua cobertura e qualidade; o de 1920 apresentou expressivo detalhamento; o de $1940^{4}$ foi um marco na história das estatísticas populacionais, tendo em vista que a partir dele houve a determinação para que os levantamentos passassem a ser decenais (OLIVEIRA; SIMÕES, 2005); e assim, sequenciadamente, foram realizados os censos de 1950, 1960, 1970, 1980, 1991, 2000 e 2010 ${ }^{5}$. As informações obtidas justificam a não realização dos censos de 1910 e 1930 em decorrência de problemas políticos e o adiamento do Censo de 1990 para 1991 devido às crises fiscais e políticas que ocorreram entre o final dos anos de 1980 e início da década de 1990.

Delineado o panorama da dinâmica territorial do Brasil e dos recenseamentos, sistematizou-se uma análise de aspectos demográficos do Rio Grande do Norte associada a eventos históricos, com base nos dados censitários, que compreende três fases a seguir explicitadas.

\section{CRESCIMENTO E DISTRIBUIÇÃO POPULACIONAL NO TERRITORIO DO RIO GRANDE DO NORTE}

$\mathrm{Na}$ perspectiva de explicitar a interrelação entre a dinâmica demográfica e os principais processos socioeconômicos que afetaram o território do Rio Grande do Norte, no período de 1872 a 2010, estabeleceu-se as seguintes fases históricas:

$1^{a}$ fase - abrange o período intercensitário de 1872 a 1920, quando o Rio Grande do Norte vivia sob a égide da produção da cana-de-açúcar no Litoral e da pecuária no Sertão.

\footnotetext{
${ }^{4}$ Esse recenciamento foi realizado pelo Instituto Brasileiro de Geografia e Estatística - IBGE, órgão criado em 1936 a partir da união de dois Conselhos, o Conselho Nacional de Estatística e o Conselho Nacional de Geografia. A partir da criação do IBGE, a coleta de dados passou a fazer parte de uma política nacional de produção de informações sobre o território brasileiro em diferentes aspectos: populacional, econômico, eleitoral, cultural. http://journals.openedition.org/terrabrasilis/102.

${ }^{5}$ Ressalta-se que as informações censitárias são coletadas no decurso de um determinado ano. Nesse sentido, decorrido o tempo de dez anos, os resultados de um dado censo refletem os processos sociais que ocorreram ao longo da década anterior.
}

Sociedade e Território - Natal. Vol. 29, N. 2, p. 84-100, Jul./Dez. de 2017. 
Todavia, na passagem do século XIX para o século XX, a emergência da cotonicultura como uma atividade econômica voltada à exportação já ensejava mudanças na estrutura produtiva do Agreste e, sobretudo do Sertão, que se tornou lócus da produção algodoeira;

$2^{\text {a }}$ fase - abrange o período intercensitário de 1940 a 1980, marcado por intensa fragmentação territorial para fins de criação de novos municípios no âmbito do estado e pelos impactos da acelerada urbanização, que se estabeleceu no contexto nacional, embora sendo regionalmente diferenciada;

$3^{\text {a }}$ fase - abrange o período intercensitário de 1991 a 2010, no qual se sobressai o processo de reestruturação territorial do estado, que assumiu nitidez nos anos de 1980, contribuindo para a configuração de um perfil demográfico predominantemente urbano.

Parte-se da premissa de que a dinâmica demográfica do Rio Grande do Norte está articulada a processos socioeconômicos que se inscrevem nas escalas regional, nacional e internacional. Nesse sentido, metodologicamente optou-se por fazer uma leitura em que a cada fase estabelecida são evidenciados aspectos do quadro político-administrativo do Brasil e do estado, seguidos dos dados populacionais e respectiva contextualização.

\section{$1^{a}$ fase: dados demográficos do Rio Grande do Norte no período 1872 a 1920}

Para a construção da análise do padrão de comportamento demográfico do Brasil e do Rio Grande do Norte, inicialmente se considerou o número de municípios e a população total no período de 1872 a 1920 (Tabela 1).

Tabela 1 - Número de Municípios e População Total do Brasil e do Rio Grande do Norte (1872/1920)

\begin{tabular}{c|c|c|c|c}
\hline \multirow{2}{*}{ Censos } & \multicolumn{2}{|c|}{ Brasil } & \multicolumn{2}{c}{ Rio Grande do Norte } \\
\cline { 2 - 5 } & $\mathrm{N}^{\circ}$ de municípios & População & $\mathrm{N}^{\circ}$ de municípios & População \\
\hline 1872 & 635 & 9930478 & 22 & 233979 \\
1890 & 1024 & 14333915 & 36 & 268273 \\
1900 & 1166 & 17438434 & 37 & 274317 \\
1920 & 1304 & 30635605 & 37 & 537135 \\
\hline
\end{tabular}

FONTE: IBGE. Disponível em: <http://www.sidra.ibge.gov.br/bda/tabela/listabl.asp?c=1290\&z=t\&o=3>. Acesso em: 2 dez 2014.

IPEA. Disponível em: <http://www.ipeadata.gov.br/>. Acesso em: 22 set. 2015.

No período em análise, houve uma ampliação no número de municípios no Brasil e no Rio Grande do Norte correspondente a $105 \%$ e $68 \%$, respectivamente. Os dados revelam que, entre 1872 e 1920, a população do Brasil obteve uma taxa de crescimento de 208,5\%, particularmente, a do Rio Grande do Norte foi de 129,6\%. Todavia, a despeito da Sociedade e Território - Natal. Vol. 29, N. 2, p. 84-100, Jul./Dez. de 2017. 
expressividade dos dados relativos, em ambos os casos, é preciso considerar que a base populacional (população absoluta) era relativamente baixa.

No que se refere à participação da população potiguar no contingente demográfico do país, verificou-se que, em 1872, correspondia a 2,36\%; em 1890, essa participação declinou para 1,87\%; em 1900, decaiu para 1,57\% e, somente em 1920 obteve uma pequena elevação $(1,75 \%)$. Verifica-se, portanto, que a participação da população potiguar no conjunto da população brasileira era pouco expressiva.

Nesse período, o padrão de comportamento demográfico do Rio Grande do Norte estava diretamente associado a dinâmica das taxas de natalidade e de mortalidade. Em termos de natalidade, é historicamente reconhecida a influência dos valores religiosos prevalecentes na época, que se refletiam em altas taxas de fecundidade e, consequentemente, nos índices de nascimento. Quanto à mortalidade, que também se apresentava alta, os escritos indicam como fatores que respondem por esse quadro: a ocorrência das secas e os abalos que produzia na frágil estrutura socioeconômica, além da proliferação de doenças, o que tornava a população extremamente vulnerável. A conjugação desses fatores definiu um padrão de crescimento da população em que, apesar das altas taxas de mortalidade, estas eram superadas por índices de natalidade ainda mais elevados, resultando em crescimento vegetativo positivo (MORAIS, 2005).

\section{$2^{\text {a }}$ fase: dados demográficos do Rio Grande do Norte no período 1940 a 1980}

O Censo de 1940 iniciou uma etapa importante na história da demografia brasileira, tendo em vista que, a partir dele, cumpriu-se a perspectiva de realização dos recenseamentos decenais, o que tornou possível a análise dos dados com base em séries temporais. Tais séries foram fundamentais para o estudo da dinâmica da população total, urbana e rural.

A Tabela 2 demonstra o número de municípios e os dados populacionais do Brasil e do Rio Grande do Norte, no período de 1940 a 1980, inclusive revelando as tendências de crescimento e de distribuição da população entre os espaços urbano e rural. 
Tabela 2: Número de Municípios e População do Brasil e do Rio Grande do Norte (1940/1980)

\begin{tabular}{|c|c|c|c|c|c|c|c|c|}
\hline \multirow{3}{*}{ Censos } & \multicolumn{4}{|c|}{ Brasil } & \multicolumn{4}{|c|}{ Rio Grande do Norte } \\
\hline & \multirow{2}{*}{$\begin{array}{l}\mathrm{N}^{\circ} \text { de } \\
\text { Muni } \\
\text { cípios }\end{array}$} & \multicolumn{3}{|c|}{ População } & \multirow{2}{*}{$\begin{array}{l}\mathrm{N}^{\mathrm{o}} \mathrm{de} \\
\text { Muni } \\
\text { cípios }\end{array}$} & \multicolumn{3}{|c|}{ População } \\
\hline & & Total & Urbana & Rural & & Total & Urbana & Rural \\
\hline 1940 & 1576 & 41236315 & 12880182 & 27356133 & 43 & 768018 & 164248 & 603770 \\
\hline 1950 & 1889 & 51944397 & 18124119 & 33820279 & 48 & 967921 & 253765 & 714156 \\
\hline 1960 & 2766 & 70312755 & 31619060 & 38693695 & 83 & 1157258 & 435189 & 722069 \\
\hline 1970 & 3952 & 93134846 & 52097260 & 41037586 & 150 & 1550244 & 737368 & 812876 \\
\hline 1980 & 4991 & 119011052 & 80437327 & 38573725 & 150 & 1898835 & 1115279 & 783556 \\
\hline
\end{tabular}

FONTE: IBGE. Recenseamento geral do Brasil - 1940: censo demográfico, censos econômicos - Rio Grande do Norte, p. 155-157.

IBGE. Estado do Rio Grande do Norte (1950): censo demográfico, p. 77-78.

IBGE. Disponível em: <http://www.sidra.ibge.gov.br/bda/tabela/ listabl.asp?c=202\&z=t\&o=3>. Acesso em 2 dez. 2014.

IPEA. Disponível em: <http://www.ipeadata.gov.br/>. Acesso: em 22 set. 2015.

Os dados apresentados são sintomáticos das mudanças que se desencadeavam na sociedade brasileira, tanto em termos de fragmentação do território para criação de municípios quanto da dinâmica populacional no que se refere às variáveis crescimento, migração e distribuição espacial.

Entre 1940 e 1980, o Brasil ampliou o número de municípios em 153\%, enquanto no Rio Grande do Norte esse índice foi de $248 \%$. Constata-se um processo de fragmentação do território potiguar, mais representativo do que aquele que ocorria em nível nacional. No Rio Grande do Norte, as décadas de 1950 e 1960 foram aquelas em que o processo de criação de municípios foi mais acelerado. A compreensão desse processo pressupõe considerar a articulação e interdependência entre fatores externos, leia-se industrialização e urbanização do país; e internos, dos quais se ressalta a reorganização das bases políticas frente à dinâmica da cotonicultura e da mineração, economias que estimularam o fenômeno urbano, sobretudo no interior no território potiguar.

Os dados relativos aos Censos de 1940 e 1980 apontam que a população do Brasil obteve uma taxa de crescimento de 188,6\%, enquanto a do Rio Grande do Norte foi de 147,23\%. A participação da população potiguar no contingente do país foi de 1,86\% em 1940; 1,86\% em 1950; 1,64\% em 1960; 1,66\% em 1970 e 1,59\% em 1980. Desse modo, o perfil verificado na fase anterior foi mantido, ou seja, a população do estado correspondia a uma ínfima parcela do contingente nacional.

No que se refere à dinâmica da população rural, verifica-se que, entre 1940 e 1980, o índice de crescimento desse contingente no Brasil foi de $41 \%$, enquanto no Rio Grande do Norte foi de apenas $29 \%$. Já em termos de população urbana, no referido período, os registros 
evidenciam um crescimento exorbitante, tanto para o Brasil (524\%) quanto para o Rio Grande do Norte (579\%). Esses indicadores refletem-se nas taxas de urbanização do país e do estado, que apresentam tendência de crescimento similar. Em 1940, a taxa de urbanização do Brasil e do Rio Grande do Norte era de 31,23\% e 21,38\%, respectivamente. Em 1980, esses percentuais corresponderam a 67,58\% para o país e 58,73\% para o estado. No Censo de 1970, registrou-se a predominância da população urbana no território brasileiro e no Censo de 1980 o Rio Grande do Norte assumiu esse perfil.

As informações censitárias do período em análise apontam para as mudanças que ocorreram no cenário brasileiro. Sobretudo na década de 1950, a introdução de uma política de modernização - e, por conseguinte, a configuração de uma nova base econômica pautada na industrialização - trouxe, entre outras consequências, a urbanização do país, processo que afetou tanto o campo como a cidade.

No campo, a modernização se efetivou, entre outras formas, a partir de conquistas para o trabalhador rural no âmbito da assistência e da seguridade social, repercutindo sobremaneira no mercado de trabalho. Isso porque, se por um lado, o trabalhador rural passou a ter os seus direitos assegurados, por outro, seu posto de trabalho foi ameaçado ou desapareceu em função do uso da máquina no processo produtivo. Assim, os direitos trabalhistas que pareciam sinônimos de garantia de trabalho e/ou a mecanização, em muitos casos, tornaram-se motivo para demissões. Além disso, a disseminação do trabalho assalariado no campo fez com que antigas relações trabalhistas como a parceria fossem preteridas, ampliando as dificuldades de permanência do pequeno produtor ou do morador no campo.

Nesse contexto, a migração do trabalhador rural para a cidade afigurou-se como alternativa, mesmo que, em muitos casos, isso não representasse o abandono da lida rural. Ademais, as significativas proporções que esse fluxo de deslocamento assumiu conformou o chamado êxodo rural, processo que foi simultâneo ao de urbanização que, apesar de apresentar-se regionalmente diferenciado, afetou todo o país. Desse modo, ratifica-se a perspectiva de pensar o processo de urbanização brasileiro no interior da " [...] reestruturação das relações entre o campo e a cidade, e, portanto, através de uma perspectiva histórica, espacializada e em uma concepção metodológica integrativa da economia rural e urbana" (CANO, 1985 apud CLEMENTINO, 1995, p. 20).

Tratando-se especificamente do Rio Grande do Norte, é preciso atentar para o quadro regional em que estava inserido. O Nordeste configurava-se nos anos de 1960 como uma "região periférica deprimida", de modo que a modernização se explicitou, entre outras formas, 
por meio do êxodo rural concomitante a uma urbanização, cujo conteúdo diferiu, substancialmente, daquele ocorrido no "core região" ou "centro" e em sua periferia imediata, as chamadas "regiões periféricas dinâmicas"6 (BECKER, 1992, p. 115). Essa diferença de conteúdo reside no fato de que a urbanização nas áreas mais dinâmicas do país estava intimamente relacionada à criação de indústrias e seu potencial enquanto atividade geradora de empregos e dinamizadora de outros setores. Sendo assim, a modernização do campo e o êxodo rural dela decorrente eram geradores de um excedente de mão de obra que, em certa medida, era absorvido pelas atividades urbanas. Entretanto, no Nordeste, particularmente em suas cidades do interior, a atividade industrial era pouco expressiva, considerando os segmentos que se localizavam na região e a capacidade de investimento que tinham essas cidades, predominantemente voltadas à economia agrária. Não obstante, algumas cidades interioranas apresentavam um certo dinamismo industrial, como por exemplo Mossoró no Rio Grande do Norte, sobretudo por meio da exploração do sal.

Nessa perspectiva, o processo de urbanização no Rio Grande do Norte, entre 1940 e 1980, foi marcado pela atuação do Estado. Nessa tessitura, entre os anos de 1950/60, houve uma expressiva multiplicação do número de cidades, via criação de novos municípios, e um crescimento das cidades existentes, por meio da expansão dos serviços (principalmente educação e saúde) e do comércio. Infere-se, portanto, que a urbanização do território potiguar manifestou-se conforme o que Santos $(1989$, p. 25) chamou de urbanização terciária, típica de áreas subdesenvolvidas, em que adquire proeminência

[...] o efeito demonstração, ou seja, a inclinação dos pobres no sentido de consumir da mesma maneira que os ricos, [...] por contribuir à atração dos homens para as cidades, local de novas atividades; no entanto não só as indústrias são aí raras como, em todo caso, os empregos permanentes não são suficientes para atender à demanda.

A diferença e a especificidade dessa urbanização residem no fato de que, embora tenha sido gestada no âmbito de um processo que assumiu uma escala nacional, não estava diretamente ligada à instalação de indústrias, mas a uma estrutura em torno do terciário, com destaque para os segmentos de comércio e serviços.

Nesse contexto, o Estado esteve à frente de ações implementadas no final da década de 1960, que repercutiram sobre a infraestrutura urbana do Rio Grande do Norte, destacando-se a

\footnotetext{
${ }^{6}$ BECKER, Bertha K. \& EGLER, Cláudio A.G. Brasil : uma nova potência regional na economia-mundo, p. 115, identificam São Paulo e Rio de Janeiro como o “core região" ou "centro” ; os estados de São Paulo, Paraná, Santa Catarina e partes do Rio de Janeiro, Minas Gerais e Rio Grande do Sul como sua periferia imediata, as chamadas "regiões periféricas dinâmicas"; o Nordeste e o entorno de Belém e de Manaus, como "regiões periféricas deprimidas".
}

Sociedade e Território - Natal. Vol. 29, N. 2, p. 84-100, Jul./Dez. de 2017. 
implementação e/ou a expansão de serviços de abastecimento de água (criação da Companhia de Águas e Esgotos do Rio Grande do Norte - CAERN), eletrificação, comunicações (telefonia), habitação (conjuntos habitacionais), transporte (rodovias e pontes), educação, saúde e sistema bancário.

Na década de 1970, a dinâmica da urbanização do Rio Grande do Norte acelerou-se, sendo ratificada a tendência de crescimento da população urbana e implementadas melhorias infraestruturais nas cidades. Nessa tessitura, ressaltam-se as ações relativas a transporte (interligação via estrada asfaltada entre Natal e Recife), comunicação (ingresso na era do DDD), habitação (adoção de programas habitacionais) e, sobretudo economia, cujos projetos foram financiados pela Superintendência do Desenvolvimento do Nordeste (SUDENE). Os principais projetos econômicos desse período foram: vilas rurais, criação de camarão em cativeiro, produção do bicho da seda e instalação do polo industrial têxtil de Natal. Esse dinamismo socioeconômico refletiu-se nos dados de 1980 ao revelar que a população urbana passou a ser superior a população rural no âmbito do estado.

A dinâmica populacional do Rio Grande do Norte, entre os anos de 1940 e 1980, foi reflexo e condicionante de um contexto histórico tecido na relação entre fatores externos e internos. Em decorrência, o padrão espacial de distribuição da população destacava-se pela crescente concentração nas cidades. Todavia, não foi apenas a taxa de urbanização, enquanto percentual da população urbana no cômputo total, que aumentou. Também adquiriu substância a urbanização enquanto processo social movido por um novo padrão de relações campo-cidade (MORAIS, 2005).

\section{$3^{\text {a }}$ fase: dados demográficos do Rio Grande do Norte no período 1980 a 2010}

Os processos socioeconômicos e espaciais desencadeados na década de 1970 no Rio Grande do Norte foram, em grande parte, responsáveis pelas novas dinâmicas territoriais que assumiram mais nitidez na década de 1980, assinalada pela reestruturação territorial, refletindo-se nos censos posteriores. A sistematização dos dados relativos ao número de municípios e a população total, urbana e rural do Brasil e do Rio Grande do Norte, no período de 1980 a 2010, pode ser visualizada na Tabela 3. 
Tabela 3: Número de Municípios e População do Brasil e do Rio Grande do Norte (1980/2010)

\begin{tabular}{|c|c|c|c|c|c|c|c|c|}
\hline \multirow[t]{3}{*}{ Censos } & \multicolumn{4}{|c|}{ Brasil } & \multicolumn{4}{|c|}{ Rio Grande do Norte } \\
\hline & \multirow{2}{*}{$\begin{array}{l}\mathrm{N}^{\mathrm{o}} \mathrm{de} \\
\text { Municí } \\
\text { pios }\end{array}$} & \multicolumn{3}{|c|}{ População } & \multirow{2}{*}{$\begin{array}{l}\mathrm{N}^{\mathrm{o}} \mathrm{de} \\
\text { Muni } \\
\text { cípios }\end{array}$} & \multicolumn{3}{|c|}{ População } \\
\hline & & Total & Urbana & Rural & & Total & Urbana & Rural \\
\hline 1980 & 3991 & 119011052 & 80437327 & 38573725 & 150 & 1898835 & 1115279 & 783556 \\
\hline 1991 & 4491 & 146825475 & 110990990 & 35834485 & 152 & 2415567 & 1669267 & 746300 \\
\hline 2000 & 5507 & 169799170 & 137953959 & 31845211 & 166 & 2776782 & 2036673 & 740109 \\
\hline 2010 & 5565 & 190755799 & 160925804 & 29829995 & 167 & 3168027 & 2464991 & 703036 \\
\hline
\end{tabular}

FONTE: IBGE. Disponível em: <http://www.sidra.ibge.gov.br/bda/tabela/listabl.asp?c=1285\&z=t\&o=3> . Acesso em: 22 set. 2015.

No interstício 1980 a 2010, os dados acerca do número de municípios denotam um crescimento de 39\% no âmbito do Brasil e de $11 \%$ no Rio Grande do Norte, revelando uma desaceleração acentuada no processo de criação de municípios no país e no estado. Nessa direção, os dados relativos ao período indicam que a população do Brasil obteve uma taxa de crescimento de $60 \%$, enquanto a do Rio Grande do Norte foi de $66 \%$. A participação da população potiguar no contingente demográfico do país, nesse período, foi de 1,6\% em 1980, 1,6\% em 1991; 1,6\% 2000; e 1,7\% em 2010. Os índices apresentados não diferem daqueles registrados nas fases anteriores, mantendo o quadro de proporcionalidade da participação da população do estado no conjunto dos habitantes do país.

O padrão de comportamento da população rural, no período 1980 a 2010, revelou uma tendência a decréscimo tanto no Brasil quanto no Rio Grande do Norte, registrando-se índices negativos: - $22 \%$ e $-10 \%$, respectivamente. As informações acerca da população urbana relativas ao período de 1980 a 2010, evidenciam a consolidação de seu crescimento no país $(100 \%)$ e no estado $(121 \%)$.

Associado ao aumento da população urbana registrou-se o crescimento das taxas de urbanização, ou seja, da participação desse contingente no cômputo da população total, tanto em nível de Brasil quanto de Rio Grande do Norte. Em 2010, o país atingiu uma taxa de urbanização de $84,36 \%$ e o estado alcançou o índice de $77,8 \%$.

A análise do padrão de comportamento populacional do Rio Grande do Norte está associada à dinâmica econômica e suas repercussões sobre o território, sendo importante considerar os processos que levaram à crise da cotonicultura (década de 1970) e da exploração scheelitífera (anos de 1980). Essas economias, voltadas para atender demandas externas (nacionais e internacionais) e consideradas importantes na pauta de exportações do estado declinaram em razão de fatores como baixo nível técnico e alto custo de produção, difícil acesso a linhas oficiais de crédito, juros elevados aplicados aos financiamentos da 
produção e preços pouco compensadores no mercado, reordenamento da geopolítica mundial com o fim da Guerra Fria, entre outros. Além disso, também é preciso levar em conta o contexto da economia global e suas articulações com o local no âmbito do estado (MORAIS, 2005). Assim, na tessitura entre fatores internos e externos, o Rio Grande do Norte foi alvo de um processo de reestruturação territorial, que tem na dinâmica econômica e populacional suas mais emblemáticas formas de manifestação.

Em termos econômicos, o Rio Grande do Norte, a partir dos anos de 1970, passou a vivenciar transformações em seu território, tanto em decorrência da crise dos pilares de sua economia (cotonicultura e mineração) quanto das intervenções estatais, sobretudo nos segmentos de produção (projetos de desenvolvimento econômico), comunicação, transporte e infraestrutura urbana. Nos anos de 1980, os alicerces dos projetos econômicos e sociais fincados na década anterior contribuíram para acelerar essas transformações.

Nesse contexto, delineou-se o processo de reestruturação produtiva, que abrange transformações de caráter estrutural, organizacional e técnico, as quais se configuram como alternativas de superação às crises cíclicas do sistema capitalista (GOMES, 2011; SILVA; AZEVEDO, 2012). A leitura da reestruturação territorial do estado pode ser entendida como "uma 'freada', senão uma ruptura nas tendências seculares", em um contexto de "mudança em direção a uma ordem e uma configuração significativamente diferentes da vida social, econômica e política", evocando "uma combinação sequencial de desmoronamento e reconstrução, de desconstrução e tentativa de reconstituição [...]”' (SOJA, 1993, p. 193-194).

Em relação às mudanças na produção do espaço potiguar, foram, em grande medida, decorrentes de incentivos estatais associados à dinâmica do capital privado, cuja articulação teceu nexos com a economia globalizada, a qual tem se mostrado seletiva em termos de espacialização. Nessa perspectiva, verifica-se que algumas áreas desempenham o papel de espaços de produção, apresentando certo nível técnico e maior densidade nas relações localglobal, sendo emblemáticas aquelas que correspondem ao Polo de Fruticultura Açu-Mossoró (abrange porções das regiões do Vale do Açu e Mossoró), à Bacia Potiguar (abrange porções das regiões Litoral Norte, Vale do Açu, Mossoró e Médio Oeste) e ao Polo Turístico do Litoral Potiguar (abrange a Região Leste).

Ademais, há áreas em que tal articulação se efetiva muito mais pela esfera do consumo ou de uma produção personalizada que atinge determinados nichos do mercado. Nesse último perfil se inserem as regiões do Seridó, Alto Oeste e Agreste, Potengi e Trairi, simetricamente situadas ao sul do território potiguar, que embora sejam afetadas pela dinâmica da Sociedade e Território - Natal. Vol. 29, N. 2, p. 84-100, Jul./Dez. de 2017. 
globalização, configuram nós que apresentam um menor grau de articulação na rede. São regiões cujos processos de formação e estruturação territorial historicamente vincularam-se à pecuária bovina, à cotonicultura e à mineração e, após as crises que envolveram essa base produtiva, passaram por um processo de diversificação da economia, porém, sem recuperar a vitalidade de outrora.

Desse modo, no cenário da globalização, as regiões Seridó, Alto Oeste e Agreste, Potengi e Trairi apresentam uma situação ambivalente em termos de integração ao sistema econômico mundial. Nessas regiões, constata-se a coexistência entre segmentos com baixos índices de produtividade e segmentos que apresentam certo potencial de inserção, inclusive por meio de uma produção personalizada, impregnada de forte conteúdo cultural. Neste último aspecto, enquadra-se a produção de alimentos, têxtil e artesanal da Região do Seridó, que se destaca pelo diferencial qualitativo da carne, do queijo, dos bordados, entre outros.

Nas regiões mencionadas, os segmentos de comércio e serviços, movidos por articulações potencializadas pelo meio técnico-científico-informacional, apresentam certo nível de desenvolvimento, tanto em termos de expansão quanto de qualificação. Entre esses segmentos, ressalta-se a ampliação dos serviços educacionais, sobretudo na modalidade a distância, por meio da oferta de cursos de graduação, técnicos e de pós-graduação.

Portanto, a compreensão da dinâmica do crescimento e da distribuição populacional do Rio Grande do Norte passa pelos meandros dos processos socioeconômicos que constituem a essência de sua reestruturação produtiva e territorial. Para Azevedo (2013, p. 116), “a combinação justaposta das diversas formas de uso do território [...] revelam a sua dinâmica, a qual se torna cada vez mais complexa, a partir da emergência de novas atividades produtivas, redefinições daquelas já existentes, bem como as práticas socioespaciais.” Emerge desse cenário um novo perfil econômico e demográfico, marcadamente urbano/terciário, embora regionalmente diferenciado.

A leitura da dinâmica demográfica do Rio Grande do Norte, no período de 1872 a 2010, revela que até o Censo de 1900, o crescimento da população apresentava um padrão estável, passando a assumir uma escala ascendente a partir do Censo de 1920. No que se refere à dinâmica da população rural e urbana do Rio Grande do Norte, cuja análise contemplou o período de 1940 a 2010, evidencia-se a configuração de tendências opostas. Os dados relativos à população rural do estado demonstram uma propensão ao crescimento até o Censo de 1970; a partir deste, instaura-se uma perspectiva declinante. A população urbana do 
estado, no período em análise, manteve a tendência de crescimento, de modo que no Censo de 1980 passou a ser predominante e consolidou esse quadro nos censos seguintes.

Mediante o exposto, é possível inferir que, ao longo da história do Rio Grande do Norte, sua dinâmica populacional foi reflexo e condicionante de processos socioeconômicos que repercutiram sobre o seu território. Nessa perspectiva, o atual perfil demográfico do estado está atrelado ao processo de reestruturação territorial, que assumiu nitidez a partir dos anos de 1980. No âmbito desse processo, consolidou-se a transição de um perfil demográfico e econômico marcadamente rural/agrário para predominantemente urbano/terciário, embora regionalmente diferenciado.

\section{REFERÊNCIAS}

AZEVEDO, Francisco Fransualdo de. Reestruturação produtiva no Rio Grande do Norte. Mercator, Fortaleza, v. 12, número especial (2), p. 113-132, set. 2013. Disponível em: www.mercator.ufc.br/mercator/article/view/1178/500. Acesso em 21 dez 2017.

BECKER, Bertha Koiffmann; EGLER, Claudio Antonio Goncalves. Brasil: uma nova potência regional na economia-mundo. Rio de Janeiro: Bertrand Brasil, 1992.

CLEMENTINO, Maria do Livramento Miranda. Economia e urbanização: o Rio Grande do Norte nos anos 70. Natal: UFRN/CCHLA, 1995.

GOMES, Maria Terezinha Serafim. O debate sobre a reestruturação produtiva no Brasil.

Revista RA'EGA. v. 21, p. 51-75, 2011. Disponível em:

<http://revistas.ufpr.br/raega/article/view/21231>. Acesso em: 21 Dez. 2017.

GUERTECHIN, Thierry Linard de. A transição demográfica como processo histórico e social da reprodução da população. Síntese: Revista de Filosofia. 1981. Disponível em:

http://faje.edu.br/periodicos/index.php/Sintese/article/viewFile/2177/2470. Acesso em $21 \mathrm{dez}$ 2017.

IBGE - INSTITUTO BRASILEIRO DE GEOGRAFIA E ESTATÍSTICA. Censos demográficos. Disponível em:

<http://www.ibge.gov.br/home/estatistica/populacao/censohistorico/1872_1920.shtm>. Acesso em: 2 dez. 2014.

Recenseamento geral do Brasil - 1940: censo demográfico, censos econômicos Rio Grande do Norte. Rio de Janeiro: Serviço Gráfico do Instituto Brasileiro de Geografia e Estatística, 1952. parte VII. Disponível em: < https://archive.org/details/censo1940vol7rn>. Acesso em: 2 out. 2015.

Estado do Rio Grande do Norte (1950): censo demográfico. Rio de Janeiro, 1956. v. XV, t. 1. Disponível em: <https://archive.org/details/censo1950vol15t1rn>. Acesso em: 2 out. 2015. 
Censos demográficos. Disponível em:

<http://www.sidra.ibge.gov.br/bda/tabela/listabl.asp?c=202\&z=t\&o=3>. Acesso em 2 dez. 2014.

IPEA - INSTITUTO DE PESQUISA ECONÔMICA APLICADA. Número de municípios do Brasil e do Rio Grande do Norte. Disponível em: 〈http://www.ipeadata.gov.br/>. Acesso em: 2 dez. 2014.

MORAIS, Ione Rodrigues Diniz. Seridó norte-rio-grandense: uma geografia da resistência. Caicó: Ed. do autor, 2005.

OLIVEIRA, Luiz Antonio Pinto de; SIMÕES, Celso Cardoso da Silva. O IBGE e as pesquisas populacionais. Revista Brasileira de Estudos Populacionais, São Paulo, v. 22, n. 2, p. 291-302, jul./dez. 2005.

SANTOS, Milton. Manual de geografia urbana. São Paulo: Hucitec, 1989.

O retorno do território. In.: SANTOS, M. SOUZA, M. A. A DE. SILVEIRA, M. L.

Território: globalização e fragmentação. 4. ed. São Paulo: EDUSP, 1998, p. 164.

SILVA, Rafael. Pereira. da; AZEVEDO, Francisco Fransualdo de. Reestruturação produtiva da pecuária bovina leiteira no Rio Grande do Norte e sua relação com o processo de desenvolvimento rural (1990-2010). In: ENCONTRO NACIONAL DE GEOGRAFIA AGRÁRIA, 21., 2012. Uberlândia. Anais... Uberlândia, 2012. p. 1-22. Disponível em: <http://www.lagea.ig.ufu.br/xx1enga/>. Acesso em: 12 ago. 2014.

SOJA, Edward William. Geografias pós-modernas: a reafirmação do espaço na teoria social crítica. Rio de Janeiro: Zahar. 1993.

VIANNA, Hélio. História do Brasil. São Paulo: Melhoramentos, 1977.

Recebido em Julho de 2017

Aprovado em Dezembro de 2017

Publicado em Dezembro de 2017 